\title{
Effect of Seed Size and Cultivar on Emergence and Stand Establishment of Broccoli in Crusted Soil
}

\author{
D.W. Heather ${ }^{1}$ and J.B. Sieczka ${ }^{2}$ \\ Department of Fruit and Vegetable Science, Cornell University, Ithaca, NY 14853 \\ Additional index words. Brassica oleracea ssp. italica, crusting resin, seed weight, direct seeding
}

\begin{abstract}
Greenhouse and field experiments were conducted in 1988 and 1989 to determine the effect of seed size and cultivar on seedling emergence through crusted soil for several hybrid broccoli cultivars (Brassica oleracea ssp. italica). Seed was separated into four sizes $(2.0,1.8,1.6$, and $1.4 \mathrm{~mm}$ in diameter) for the greenhouse investigations, and soil crusting was achieved using a crusting resin. In 1989, field experiments using three seed sizes (small $=1.4$ to $1.6 \mathrm{~mm}$, medium $=1.7$ to $1.9 \mathrm{~mm}$, and large $=2.0$ to $2.2 \mathrm{~mm}$ in diameter) were planted at the Long Island Horticultural Research Laboratory in a Riverhead sandy loam that crusted readily following rainfall. Seedling emergence data from the greenhouse and field studies indicate that seed size and cultivar significantly affect emergence and stand establishment. Seedling stand, dry weight, and final yield significantly increased as seed size increased for both cultivars in the field experiments. The emergence of 'Mariner' generally was significantly better than that of 'Greenlady' for each seed size. Seed of 'Greenlady' also weighed significantly less than that of 'Mariner' within each seed size tested.
\end{abstract}

Soil crusting can result in irregular emergence and poor plant stands of direct-seeded crops, which ultimately decrease harvest concentration and yield. This irreparable loss of early stand uniformity can be severe with small-seeded vegetable crops, resulting in economic losses to growers. When seedling stands are optimized, a greater concentration of harvest maybe achieved, which, in turn, results in increased harvest efficiency and decreased harvesting costs.

Hegarty and Royle (1978) found a close relationship between the percent emergence of broccoli and soil impedance. Weaver (1980) went further to show that dicots, such as broccoli emerge through a crusted soil with greater difficulty than do monocots due to the increased surface area that must penetrate the crusted soil surface.

Taylor and Ten Broeck (1988) demonstrated that the amount of seedling emergence force expended increased linearly as seed size increased for an array of small- to large-seeded vegetable crops. However, Bremner et al. (1963) found that smaller seeds were more efficient in using reserve materials than larger ones. They concluded that the amount of reserve material available to the developing seedling is a dominant factor in the emergence force potential. They also showed that while embryo size had no significant effect on overall growth, endosperm size did. While this may be true for monocots, studies with carrot (Daucus carrota L.) seed indicated that mean emergence time decreased and percent emergence increased with increased embryo length of heavier seeds (Gray and Steckel, 1983).

Within the Cruciferae, numerous studies have linked varia-

Received for publication 20 Feb. 1991. Paper no. 9 of the Dept. of Fruit and Vegetable Science, Cornell Univ. A portion of a thesis submitted by D.W.H. as partial fulfillment of the requirements for the MS at Cornell Univ. We gratefully acknowledge the technical assistance provided by Robert Neese and Mark Sisson. We also acknowledge the assistance of Allen Taylor, who provided the crusting resin used in these experiments. The cost of publishing this paper was defrayed in part by the payment of page charges. Under postal regulations, this paper therefore must be hereby marked advertisement solely to indicate this fact.

'Graduate Research Assistant. Present address: Dept. of Plant Breeding and Biometry, Cornell Univ., Ithaca, NY 14853.

${ }^{2}$ Associate Professor, Long Island Horticultural Research Laboratory, Riverhead, NY 11901. bility of seedling emergence through crusted soils with seed size. Lang and Holmes (1964) demonstrated that emergence was significantly higher for large than for small rutabaga seed. Cummings (1914) showed that larger seed resulted in higher emergence and overall yield for the cultivated radish. Many studies have also been done involving wild radish (Raphanus raphanistrurn L.), a persistent weed in many areas. Stanton (1985) found 6-fold differences in seed mass within a single seed pod. Large seeds were found to grow more rapidly and developed plants that produced more flowers than smaller seed. Stanton concluded that reproductive fitness was influenced more by seed weight than emergence time. Tompkins (1965) studied the effects of seed size on maturity and yield of several broccoli cultivars. Although the effects of soil crusting were not assessed, transplants grown from large seed had significantly higher early yields than those from small seed.

In the wild, seed size variation may have offered a survival mechanism whereby smaller seeds would disperse farther away from the mother plant upon pod dehiscence (Temme, 1986). In modern agricultural systems, where economics mandate harvest efficiency, there may be advantages in using selected large seed for the production of small-seeded crops. Large seed size may be especially beneficial for the direct seeding of broccoli in soils prone to crusting. Greenhouse and field experiments were conducted to assess the effect of seed size and cultivar on seedling emergence, dry weight, and yield of direct-seeded broccoli.

\section{Materials and Methods}

Growth chamber and greenhouse experiments. Based on the results of an experiment conducted in 1988 comparing the emergence of 11 hybrid broccoli cultivars in crusted vs. noncrusted soil (data not shown), six were selected to verify differences between cultivars. Two cultivars of each of the following emergence classifications were selected: good ('Emperor' and 'Mariner'), medium ('Cruiser' and 'Packman'), and poor ('Royal Green' and 'Greenlady'). The six cultivars consistently fell into the above ranking of emergence in 10 replications of the 1988 experiment. Seeds of the six cultivars were passed through screens, and 1.7 - to $1.9-\mathrm{mm}$-diameter seed was used to verify emergence potential. Seeds were than planted in flats filled with equal volumes of a mixture of 7 peat-vermiculite $(50 / 50, v / v): 3$ fine 
builders sand : 1 kaolinite clay. The sand and clay fractions were added to increase bulk density and enhance the effectiveness of the crusting agent (50\% solution of Gelva resin TS-85; Monsanto, St. Louis). Ten seeds of each cultivar were planted in each of 20 flats in rows $18 \mathrm{~cm}$ long with $2 \mathrm{~cm}$ between rows and between seeds within the rows. Planting depth was $15 \mathrm{~mm}$, and a guard row was seeded around the perimeter of each flat to avoid border effects. Following seeding and watering, half of the 20 flats were randomly selected and sprayed with the crusting resin, resulting in 10 replicated flats per cultivar per treatment. Capillary watering was used thereafter to maintain soil crust integrity, and the flats were held in a growth chamber at 20C. Early mean percent "emergence data were collected 5 days from seeding and final mean percent emergence data were recorded after 20 days.

To determine the relationship between emergence potential and seed size and weight distribution, commercially obtained 28 -g samples of each of the six cultivars were separated into seed sizes of 1.4, 1.6, 1.8, 2.0, and $2.2 \mathrm{~mm}$ using mesh screens. 'Mariner' and 'Emperor' were found not to have seeds larger than $2.0 \mathrm{~mm}$ in diameter; therefore, subsequent experiments focus only on the 1.4-to 2.0-mm range. Two replicate seed lots obtained in 1988 and 1989 were used to calculate the mean percentage (by weight) of seed falling into each of the size classes. Seed of the two cultivars with the greatest emergence potential ('Emperor' and 'Mariner') and two with the lowest emergence potential ('Royal Green' and 'Green Lady') were further separated into 1.4-, 1.6-, 1.8-,. and 2.0-mm-diameter seed sizes, and seed weight was determined by weighing 1000 randomly selected seeds for each cultivar. Four replications of 'Emperor', 'Mariner', 'Royal Green', and 'Greenlady' seed were compared, and mean separation was calculated using the WallerDuncan k ratio $t$ test at $P=0.05$.

Two additional greenhouse experiments were seeded on 10 and 17 Feb. 1989 to further test seedling emergence of four seed sizes for 'Mariner' and 'Greenlady' hybrid broccoli in crusted vs. noncrusted soil. The design was a split-split plot, with soil crusting as the main plot, seed sizes as subplots, and cultivars as sub-subplots, with five replications. The flats were held at a mean of 24C day/20C night in a greenhouse using natural light. Seedling emergence data were collected 7 days after seeding.

Field experiments. In Summer 1989, the effect of seed size on the emergence of 'Mariner' and 'Greenlady' was tested in the field at the Long Island Horticultural Research Lab., Riverhead, N.Y. Both seed lots were passed through sizing screens and separated into three size classes (small $=1.4$ to $1.6 \mathrm{~mm}$, medium $=1.7$ to $1.9 \mathrm{~mm}$, and large $=2.0$ to $2.2 \mathrm{~mm}$ in diameter).

A split-plot randomized complete block design with four replications was used with cultivars as the main plots and the three seed sizes as the subplots. Eighty seeds of each cultivar in each size class were drilled in rows $4 \mathrm{~m}$ long with a Stanhay belt seeder using three belts with 1.6-, 1.9-, and 2.2-mm holes punched for the small, medium, and large seed, respectively. For all three belts, the spacing between holes was $5 \mathrm{~cm}$. The betweenrow. spacing was $86 \mathrm{~cm}$, and data were collected from the center $3 \mathrm{~m}$ of each row. Each block had guard rows planted on either side and 1.5-m unplanted buffers.

Emergence data were collected 4, 6, and 8 days after seeding, and the stand was thinned to an average of $15 \mathrm{~cm}$ between plants after 2 weeks. The experiment was repeated in three separate plantings, with the first and third being harvested for final yield. In the second experiment, 2-week-old seedlings were randomly selected from each size class and dry weights were determined. All three experiments experienced heavy rainfall after planting, which consistently formed a surface crust having a mean mechanical resistance of $0.91 \mathrm{MPa} \pm 0.58$, as measured from 20 random samples per experiment with a model CL-700 soil penetrometer (Soiltest, Evanston, Ill.).

Analysis of variance was computed using the general linear models (GLM) procedure of SAS.

\section{Results}

Growth chamber experiment. In the growth chamber experiment conducted in 1989 at 20C, significant differences were found both between cultivars and between crusted vs. noncrusted soil (Fig. 1). 'Emperor' and 'Mariner' had the highest emergence in noncrusted and crusted treatments. 'Greenlady' had the lowest percent emergence of the six cultivars tested. The significant differences in emergence between cultivars in the noncrusted control were consistent with 1988 data. The emergence of 'Emperor' after 5 days was nearly equal to the final emergence. However, the final percent emergence for 'Greenlady' was significantly higher than the early emergence (Fig. 1). The mechanical resistance for the crusted and the control soil was $0.44 \pm 0.06 \mathrm{MPa}$ and $0.16 \pm 0.01 \mathrm{MPa}$, respectively. These resistance values did not differ significantly from the 1988 readings.

Cultivars from commercial seed lots with a prior record of poor to medium emergence had the highest proportion of seed, by weight, fall into the $2.0-\mathrm{mm}$ size, while the two cultivars showing better emergence ('Emperor' and 'Mariner') had a higher proportion of 1.8-mm seed (Table 1). 'Emperor' and 'Mariner'

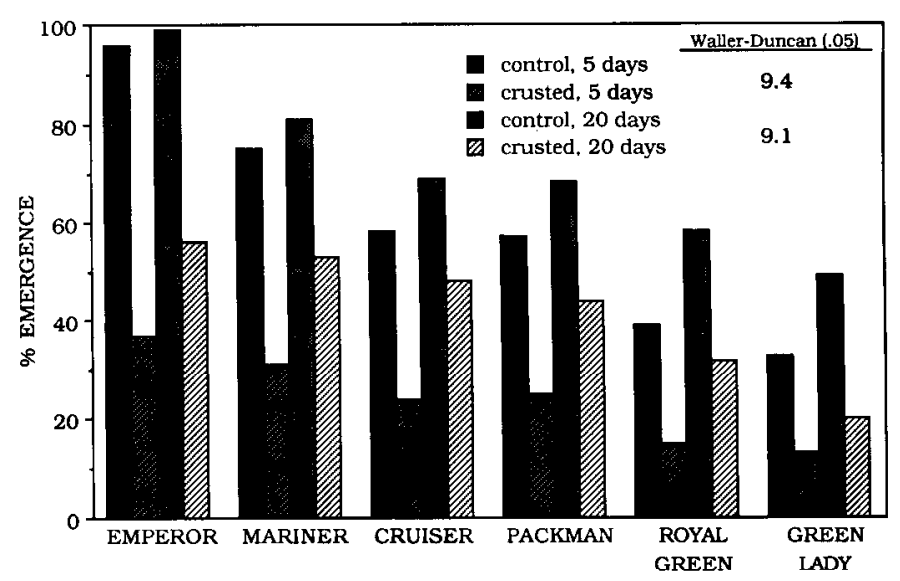

Fig. 1. Mean percent emergence of six hybrid broccoli cultivars through a crusted soil vs. noncrusted control at 20C in 1989. Early emergence data collected 5 days after planting and final emergence recorded after 20 days.

Table 1. Seed diameter and mean (\&SE) weight distribution for 28$\mathrm{g}$ samples of six hybrid broccoli cultivars.

\begin{tabular}{|c|c|c|c|c|c|}
\hline \multirow[b]{3}{*}{ Cultivar } & \multicolumn{5}{|c|}{ Seed diam $(\mathrm{mm})$} \\
\hline & 2.2 & 2.0 & 1.8 & 1.6 & 1.4 \\
\hline & \multicolumn{5}{|c|}{ Percent (by wt) in each size class } \\
\hline Greenlady & $31 \pm 3$ & $48 \pm 3$ & $12 \pm 1$ & $7 \pm 1$ & $2 \pm 0.1$ \\
\hline Royal Green & $13 \pm 2$ & $57 \pm 2$ & $21 \pm 0.3$ & $7 \pm 0.1$ & $2 \pm 0.2$ \\
\hline Packman & $13 \pm 1$ & $63 \pm 1$ & $21 \pm 1$ & $3 \pm 0.1$ & 0 \\
\hline Cruiser & $5 \pm 1$ & $72 \pm 3$ & $16 \pm 3$ & $5 \pm 0.3$ & $2 \pm 0.1$ \\
\hline Mariner & 0 & $26 \pm 3$ & $59 \pm 3$ & $14 \pm 0.8$ & $1 \pm 0.1$ \\
\hline Emperor & 0 & $21 \pm 2$ & $52 \pm 2$ & $23 \pm 0.7$ & $4 \pm 0.7$ \\
\hline
\end{tabular}


did not have any seed larger than $2.0 \mathrm{~mm}$ in diameter, while the other four cultivars had 2.2-mm-diameter seed. 'Greenlady' had the greastest proportion of 2.2-mm-diameter seed and the poorest percent emergence.

The significance of these results became clearer when the seed weight of the two cultivars with good emergence ('Emperor' and 'Mariner') were compared to the seed weight of the two cultivars of poor emergence ('Royal Green' and 'GreenIady'). 'Greenlady' had significantly lower mean seed weight than 'Mariner' or 'Emperor' in all four size classes (Table 2). Mean weight of 1000 'Royal Green' seeds was significantly lower than that of 'Mariner' and 'Emperor' only in the 1.6- and 1..8-mm size classes.

The emergence of 'Mariner' and 'Greenlady' seed was compared at four seed sizes in crusted vs. noncrusted soil. In general, both cultivar and seed size significantly affected seedling emergence (Table 3): Emergence increased significantly in crusted soil as seed size increased for 'Greenlady'. The 2.0- and 1.8$\mathrm{mm}$ sizes were not significantly different from each other for 'Mariner'; however, emergence of the 2.0- and 1.8-mm seed was significantly higher than the 1.6- and 1.4-mm sizes. Fewer significant differences were detected in response to seed size in the noncrusted treatment. A significant increase in emergence was observed for 2.0-mm-diameter 'Greenlady' seed in comparison with 1.4- to $1.8-\mathrm{mm}$ sizes in the second experiment.

Emergence was significantly affected by cultivar in the noncrusted treatments of both experiments. Emergence of 'Mariner' in noncrusted soil was lower in the second experiment than the first, while emergence of 'Greenlady' differed little between experiments.

Field studies. 'Mariner' and 'Greenlady' were selected for the 1989 field study based on differences in emergence in prior greenhouse experiments, as well as seed weight data (Table 2). Large $(2.0-2.2 \mathrm{~mm})$ seed resulted in significantly earlier emergence than small $(1.4-1.6 \mathrm{~mm})$ seed for both cultivars (Table

Table-2. Mean weight for 1000 seeds within four size classes of four hybrid broccoli cultivars.

\begin{tabular}{lcccc}
\hline \hline & \multicolumn{4}{c}{ Seed diam $(\mathrm{mm})$} \\
\cline { 2 - 5 } & 2.0 & \multicolumn{4}{c}{1.8} & 1.6 \\
\cline { 2 - 5 } Cultivar & $5.8 \mathrm{a}$ & $5.2 \mathrm{a}$ & $4.3 \mathrm{a}$ & $3.3 \mathrm{a}$ \\
\hline Emperor & $5.6 \mathrm{a}$ & $5.0 \mathrm{a}$ & $4.1 \mathrm{a}$ & $3.1 \mathrm{ab}$ \\
Mariner & $5.7 \mathrm{a}$ & $4.3 \mathrm{~b}$ & $3.5 \mathrm{~b}$ & $2.9 \mathrm{bc}$ \\
Royal Green & $4.9 \mathrm{~b}$ & $3.8 \mathrm{C}$ & $3.3 \mathrm{~b}$ & $2.7 \mathrm{c}$ \\
Greenlady & &
\end{tabular}

'Mean separation within columns by the Wailer-Duncan $\mathrm{k}$ ratio $t$ test, $P=0.05$.

Table 3. The effect of soil crusting and seed size on mean $( \pm \mathrm{SE})$ percent emergence of 'Mariner' and 'Greenlady' hybrid broccoli 7 days after planting, 1989.

\begin{tabular}{lcccccc}
\hline & \multirow{2}{*}{$\begin{array}{c}\text { Seed } \\
\text { diam }\end{array}$} & \multicolumn{2}{c}{ Expt. 1 } & & \multicolumn{2}{c}{ Expt. 2 } \\
\cline { 7 - 7 } \cline { 5 - 6 } Crusting & $(\mathrm{mm})$ & Mariner & Greenlady & & Mariner & Greenlady \\
\hline None & 2.0 & $89 \pm 2.3$ & $56 \pm 3.9$ & & $82 \pm 2.6$ & $63 \pm 4.1$ \\
& 1.8 & $86 \pm 2.5$ & $53 \pm 1.6$ & $78 \pm 2.9$ & $51 \pm 1.8$ \\
& 1.6 & $85 \pm 2.1$ & $51 \pm 1.9$ & & $81 \pm 2.1$ & $50 \pm 2.3$ \\
& 1.4 & $81 \pm 3.4$ & $49 \pm 2.0$ & $77 \pm 2.8$ & $48 \pm 2.1$ \\
Crusted & 2.0 & $52 \pm 1.9$ & $33 \pm 3.5$ & $38 \pm 7.1$ & $38 \pm 3.0$ \\
& 1.8 & $50 \pm 1.8$ & $22 \pm 2.1$ & & $32 \pm 5.8$ & $32 \pm 2.7$ \\
& 1.6 & $34 \pm 2.7$ & $11 \pm 1.9$ & & $13 \pm 5.6$ & $17 \pm 2.1$ \\
& 1.4 & $19 \pm 3.1$ & $4 \pm 3.3$ & $11 \pm 3.9$ & $10 \pm 2.9$ \\
\hline \hline
\end{tabular}

4). The large seed classes also led to consistently higher final stands after thinning and significantly higher total yields. The small seed of 'Mariner' produced significantly better stands than 'Greenlady' of the same size. The majority of rows planted with small 'Greenlady' seed had total emergence of one or less seedlings per $3 \mathrm{~m}$. The other major difference between cultivars is that there were greater differences in emergence between the large (2.0-2.2 mm) and medium (1.7-1.9 mm) seed sizes with 'Greenlady' than with 'Mariner'. This result agrees with the data for the crusted surface in the greenhouse investigation (Table 3, Expt. 1). Cultivar $\mathrm{x}$ seed size interactions were significant at $P=0.014$ to 8 days after seeding, at $P=0.05$ for final stand, and nonsignificant for the pooled yield data (Table 4). Significant differences in yield (fresh weight) were consistently observed in all three field experiments.

\section{Discussion}

The importance of good stand establishment in broccoli production is paramount since uniform seedling stands maximize

Table 4. Effect of seed size on the emergence, dry weight, and yield of field-seeded 'Mariner' and 'Greenlady' hybrid broccoli at the Long Island Horticultural Research Lab., Riverhead, N. Y., in 1989.'

\begin{tabular}{|c|c|c|c|c|c|c|c|}
\hline \multirow[b]{3}{*}{ Cultivar } & \multirow{3}{*}{$\begin{array}{l}\text { Seed } \\
\text { diam } \\
(\mathrm{mm})\end{array}$} & \multirow{2}{*}{\multicolumn{3}{|c|}{$\begin{aligned} & \text { Seedling } \text { stand } \\
& \text { (days after } \text { planting) } \\
&\end{aligned}$}} & \multirow{3}{*}{$\begin{array}{l}\text { Final } \\
\text { stand }\end{array}$} & \multicolumn{2}{|c|}{ Measurement } \\
\hline & & & & & & \multirow{2}{*}{\multicolumn{2}{|c|}{$\begin{array}{l}\text { Dry wt/ } \\
\text { Yield seedling } \\
(\mathrm{kg} / \mathrm{plot})(\mathrm{mg})\end{array}$}} \\
\hline & & 4 & 6 & 8 & & & \\
\hline \multicolumn{8}{|c|}{ Expt. 1} \\
\hline \multirow[t]{3}{*}{ Mariner } & $1.4-1.6$ & 8.3 & 10.0 & 11.3 & 7.0 & 1.1 & \\
\hline & $1.7-1.9$ & 28.3 & 32.8 & 33.5 & 14.0 & 2.8 & \\
\hline & $2.0-2.2$ & 33.3 & 38.8 & 41.5 & 17.0 & 3.2 & \\
\hline \multirow[t]{3}{*}{ Greenlady } & $1.4-1.6$ & 0.0 & 1.0 & 1.0 & 0.5 & 0.1 & \\
\hline & $1.7-1.9$ & 1.8 & 5.5 & 5.8 & 4.5 & 1.3 & \\
\hline & $2.0-2.2$ & 11.0 & 20.0 & 21.3 & 13.3 & 2.9 & \\
\hline \multicolumn{8}{|c|}{ Expt. 2} \\
\hline \multirow[t]{3}{*}{ Mariner } & $1.4-1.6$ & 4.5 & 9.5 & 10.5 & 6.5 & & 28.0 \\
\hline & $1.7-1.9$ & 24.5 & 32.0 & 34.0 & 14.3 & & 40.0 \\
\hline & $2.0-2.2$ & 32.5 & 37.5 & 39.7 & 16.5 & & 61.0 \\
\hline \multirow[t]{3}{*}{ Greenlady } & $1.4-1.6$ & 0.0 & 0.5 & 1.0 & 0.8 & & 12.0 \\
\hline & $1.7-1.9$ & 0.8 & 3.8 & 4.3 & 2.5 & & 28.0 \\
\hline & $2.0-2.2$ & 8.3 & 16.5 & 18.0 & 11.8 & & 57.0 \\
\hline \multicolumn{8}{|c|}{ Expt. 3} \\
\hline \multirow[t]{3}{*}{ Mariner } & $1.4-1.6$ & 1.3 & 9.5 & 10.5 & 7.3 & 1.5 & \\
\hline & $1.7-1.9$ & 4.8 & 19.3 & 20.3 & 12.8 & 2.6 & \\
\hline & $2.0-2.2$ & 12.0 & 28.0 & 29.0 & 16.0 & 3.1 & \\
\hline \multirow[t]{3}{*}{ Greenlady } & $1.4-1.6$ & 0.0 & 1.0 & 1.3 & 1.0 & 0.1 & \\
\hline & $1.7-1.9$ & 1.0 & 9.3 & 10.3 & 8.0 & 1.4 & \\
\hline & $2.0-2.2$ & 6.3 & 18.3 & 19.5 & 13.3 & 2.5 & \\
\hline \multicolumn{8}{|c|}{ Significance ${ }^{v}$} \\
\hline \multicolumn{2}{|l|}{ Cultivar } & $* *$ & $* *$ & $* *$ & $* *$ & $*$ & $* *$ \\
\hline \multicolumn{2}{|c|}{ Seed size } & $* *$ & $* *$ & $* *$ & $* *$ & $* *$ & $* *$ \\
\hline \multicolumn{2}{|c|}{$\begin{array}{l}\text { Cultivar } \times \text { seed } \\
\text { size }\end{array}$} & $* *$ & ** & $* *$ & $*$ & NS & $* *$ \\
\hline
\end{tabular}

zPlanting dates: Expt. 1 = 9 May 1989 and Expts. 2 and $3=30$ May 1989.

${ }^{y}$ Seedling stand is the total number of seedlings emerged per $3 \mathrm{~m}$ of row 4,6 , and 8 days after planting. Maximum stand $=60$ plants.

'Final stand count was made 2 weeks after seeding and after thinning the stand to an average of $15 \mathrm{~cm}$ between plants. Maximum $=20$ plants.

wDry weights are from randomly sampled 2-week-old seedlings.

"Pooled for all three experiments, except yield, which is pooled from Expts. 1 and 3 and dry weight, which is only for Expt. 2.

Ns,*,**Nonsignificant or significant at $P=0.05$ or 0.01 , respectively. 
the chances for increased harvest concentration at maturity. This has been shown to be true for transplanted and direct-seeded crops (Cochran, 1974). While many vegetable growers choose transplanting to achieve uniformity, this study suggests that direct seeding of broccoli may be a very viable alternative for production on light-textured soils.

This study shows that emergence of broccoli through crusted soil is affected by cultivar, seed size, and seed weight. Many additional years of seed testing would be necessary before any solid conclusions could be made as to true cultivar differences. However, seed that consistently emerged the best was large and heavy. 'Greenlady' had not only the lightest seed, but also typically had shriveled rather than smooth seedcoats in the two years tested. The seed of cultivars with the highest emergence typically" had the bulk of the sample in the 1.8-mm size (Table 1 ). While this distribution may simply bean artifact of the seed cleaning and handling process, medium-sized seed of the bestemerging cultivars was often similar or better in emergence to large seed of a cultivar with poor emergence (Table 4). Thus, seed weight is an important component of larger seed size. Indeed, seed weight appears to be a critical factor in emergence potential since the weight of medium $(1.8 \mathrm{~mm})$ 'Mariner' seed was shown not to differ significantly from that of large (2.0 mm) 'Greenlady' seed (Table 2), while the medium 'Mariner' seed often had better early emergence than large 'Greenlady' seed (Tables 3 and 4). This result suggests that 'Mariner' may be more efficient than 'Greenlady' in the hydrolysis of storage reserves during germination. Other factors affecting seedling emergence, both genetic and environmental, also play a role in seedling stand. However, the use of large, heavy seed has been shown to be a major factor in the optimization of broccoli seedling emergence in crusted soil. The consistent pattern of emergence in crusted soil between 'Mariner' and 'Greenlady' observed in the field experiments supports the use of large or heavy seed. Some of the inconsistencies in the greenhouse investigations may have been due to differences in the crusting resin that were not detected by penetrometer readings.

Commercially, there may be some benefit in using heavy or large seed for direct seeding of broccoli in the field. The stand enhancement achieved with the large seed is perhaps most critical with cultivars having poor emergence but otherwise outstanding horticultural characteristics. This was the case for field plantings of 'Greenlady', in which only the largest seed (2.0-
$2.2 \mathrm{~mm}$ ) resulted in a commercially viable stand (Table 4). Even when seeding belts that have holes large enough to allow large seeds to drop are used, it appears that the bulk of the smallest seed may never emerge in heavy or crusted soil and is wasted. While most commercially packed seed is presized or precisiongraded to provide a bulk of seed of high emergence potential, it may be beneficial to rescreen seed samples and select the largest, heaviest seed for maximum emergence and field performance. This may be advantageous not only to commercial growers desiring large, uniform harvests, but aIso in experimental situations assessing such factors as earliness or yield. By stringently size-screening seed and using a constant size range, much of the variability in emergence would be eliminated and a more uniform harvest and accurate assessment of production variables would be possible.

\section{Literature Cited}

Bremner, P. M., R.N. Eckersall, and R.K. Scott. 1963. The relative importance of embryo and endosperrn size in causing the effects associated with seed size in wheat. J. Agr. Sci. 61: 139-145.

Cochran, H.C. 1974. Effect of seed size on uniformity of pimento transplants (Capsicum annuum L.) at harvest time. J. Amer. Sot. Hort. Sci. 99:234-235.

Cummings, M.B. 1914. The effects of seed size on radish germination and emergence. Vermont Agr. Station Bul. 117.

Gray, D. and J.R.A. Steckel. 1983. Some effects of umbel order and harvest date on carrot seed variability and seedling performance. J. Hort. Sci. 58:73-82.

Hegarty, T.W. and S.M. Royle. 1978. Soil impedance as a factor reducing crop seedling emergence, and its relation to soil conditions at sowing, and to applied water. J. Applied Ecol. 15:897-904.

Lang, R.W. and J.C. Holmes. 1964. The growth of the swede crop in relation to seed size. J. Agr. Sci. 63:221-227.

Stanton, M.L. 1985. Seed size and emergence time within a stand of wild radish (Raphanus raphanistrum L.): The establishment of a fitness hierarchy. Oecolegia

Taylor, A.G. and C.W. Ten Broeck. 1988. Seedling emergence forces of vegetable crops. HortScience 23:367.

Temme, D.H. 1986. Seed size variability: A consequence of variable genetic quality among offspring? Evolution 40:414-417.

Tompkins, D.R. 1965. Broccoli maturity and production as influenced by seed size. J. Amer. Sot. Hort. Sci. 88:400-405.

Weaver, K.N. 1980. Field emergence of calabrese and onion seedlings in response to compaction treatments on the soil surface or at seed depth. J. Hort. Sci. 55(4)325-332. 